\title{
Symposium
}

\section{Time in Cortical Circuits}

\author{
Gerald T. Finnerty, ${ }^{1}$ Michael N. Shadlen, ${ }^{2}$ Mehrdad Jazayeri, ${ }^{3}$ Anna C. Nobre, ${ }^{4}$ and Dean V. Buonomano ${ }^{5,6}$ \\ ${ }^{1}$ Department of Basic and Clinical Neuroscience, Institute of Psychiatry, Psychology and Neuroscience, King's College London, London SE5 8AF, United \\ Kingdom, ${ }^{2}$ Department of Neuroscience, Zuckerman Mind Brain Behavior Institute, Columbia University, New York, New York 10032, ${ }^{3}$ Department of \\ Brain and Cognitive Sciences, McGovern Institute for Brain Research, Massachusetts Institute of Technology, Massachusetts 02139, ${ }^{4}$ Department of \\ Experimental Psychology, University of Oxford, Oxford OX1 3UD, United Kingdom, and ${ }^{5}$ Department of Neurobiology and ${ }^{6}$ Department of Psychology, \\ Brain Research Institute, University of California, Los Angeles, California 90095
}

Time is central to cognition. However, the neural basis for time-dependent cognition remains poorly understood. We explore how the temporal features of neural activity in cortical circuits and their capacity for plasticity can contribute to time-dependent cognition over short time scales. This neural activity is linked to cognition that operates in the present or anticipates events or stimuli in the near future. We focus on deliberation and planning in the context of decision making as a cognitive process that integrates information across time. We progress to consider how temporal expectations of the future modulate perception. We propose that understanding the neural basis for how the brain tells time and operates in time will be necessary to develop general models of cognition.

\section{Significance Statement}

Time is central to cognition. However, the neural basis for time-dependent cognition remains poorly understood. We explore how the temporal features of neural activity in cortical circuits and their capacity for plasticity can contribute to time-dependent cognition over short time scales. We propose that understanding the neural basis for how the brain tells time and operates in time will be necessary to develop general models of cognition.

\section{Introduction}

Time plays a key role in cognition. Our experiences and thoughts occur in the present and are stored as the past. We combine the present and the past to anticipate events, direct attention, make decisions, and formulate plans for the future. In the remote past, our capacity to predict and anticipate the actions of predators, prey, and environmental events enhanced our ability to survive and to reproduce. In the modern world, the value of time to human cognition is immediately visible in the clinical setting. When patients become disorientated in time, their cognitive capacities degrade and their ability to function independently declines. Although time is vital for normal cognition, our understanding of the neural basis for time-dependent cognition remains rudimentary.

Received July 12, 2015; revised Aug. 28, 2015; accepted Aug. 31, 2015.

This work was supported by the Wellcome Trust (G.T.F., A.C.N.), the Medical Research Council (G.T.F.), the National Institute of Mental Health-National Institutes of Health (D.V.B.), the National Science Foundation (D.V.B.), the National Institutes of Health (M.N.S.), the Howard Hughes Medical Institute (M.N.S.), and the Human Frontiers Science Project (M.N.S.). We thank Sam Barnes, Liu Yan, and Sophie Bennett for constructive comments.

The authors declare no competing financial interests.

Correspondence should be addressed to Gerald T. Finnerty, Department of Basic and Clinical Neuroscience, Institute of Psychiatry, Psychology and Neuroscience, King's College London, 16 De Crespigny Park, London SE5 8AF, UK. E-mail: gerald.finnerty@kcl.ac.uk.

DOI:10.1523/JNEUROSCI.2654-15.2015

Copyright $\odot 2015$ the authors $\quad 0270-6474 / 15 / 3513912-05 \$ 15.00 / 0$
Psychophysical experiments have explored the relationship between time and cognition (Fraisse, 1964, 1984). However, there remains a large explanatory gap between psychological studies of time and our knowledge of the neural circuits that generate our perception of time. In this review, we aim to bridge that gap by building from both the bottom up and from the top down. We start with bottom-up approaches that explore how neural circuits use time. Here, time refers to "physical time," that is, time measured with chronometers. The questions focus on the temporal properties of signaling between cortical neurons, how that signaling can be modified, and what the signaling may contribute to time-dependent cognition. Building from the top down, we consider cognitive processes that involve time as we perceive it (Fraisse, 1964, 1984; Allman et al., 2014). We focus on cognitive processes that operate in the present or anticipate events or stimuli in the near future. The scientific questions focus on the activity of single neurons or populations of neurons in behaving subjects. Finally, we seek to combine advances from the reductionist and the intact-subject approaches to explore how recent work is laying the foundations for a deeper understanding of the neural basis for time-dependent cognition.

Inevitably, we have had to be highly selective. There are excellent reviews on the role of internal clocks in time perception (Allman et al., 2014). Similarly, numerous insightful reviews discuss the past and memory (Martin et al., 2000; Frankland and 
Bontempi, 2005; Silva et al., 2009). Several brain regions have been implicated in time-dependent cognition. We focus on cortical circuits. Comprehensive reviews consider the contribution to time-dependent cognition of extracortical brain regions, such as the basal ganglia and cerebellum (Ivry, 1996; Merchant et al., 2013).

\section{Time, timing, and plasticity of cortical microcircuits}

Signaling between two neurons has temporal properties that could be used as building blocks for time-dependent cognition. Most obviously, communication between two neurons takes time. An action potential has to propagate down an axon and invade the axon's presynaptic terminals to elicit release of neurotransmitter. The neurotransmitter then diffuses across the synaptic cleft and evokes a postsynaptic response (Katz and Miledi, 1965; Sabatini and Regehr, 1996). The time taken for the entire series of events is referred to as the synaptic latency. Despite the multiplicity of processes, the synaptic latency usually remains relatively constant for any given connection in mature cortex, even when the connection is activated repeatedly $(<40 \mathrm{~Hz})$ (Barnes et al., 2015). The time course of the excitatory postsynaptic response is modified by factors intrinsic to the postsynaptic neuron (e.g., passive membrane properties, ion channel distribution) and by inhibition. Therefore, the time window over which an excitatory input contributes to firing of the postsynaptic neuron can be narrowed or widened by adjusting the temporal profile of the postsynaptic response that the excitatory input evokes (Pouille and Scanziani, 2001).

Temporal information is not just encoded in the temporal characteristics of neural activity. The frequency of activation of a neuron-to-neuron connection affects the amplitude of the postsynaptic response (Zucker and Regehr, 2002). This variation is referred to as either the short-term synaptic dynamics or shortterm synaptic plasticity. The consequence of synaptic dynamics is that each synaptic response carries information about the recent history of activity at that synapse.

In neuronal networks, the temporal properties of neural activity may be characterized by measuring the time difference between neurophysiological events such as action potential firing or postsynaptic responses. This raises an important point when discussing the role of time and temporal processing in brain function. A crucial distinction should be made between the timing of neurophysiological events and the ability to tell time. Inevitably, the timing of neurophysiological processes and the ability to tell time intersect because the only way to tell time is to use mechanisms that play out or change in time in some reproducible fashion.

The timing of neural activity has been implicated in long-term plasticity processes that enable mature networks to learn temporal processing (Feldman, 2012). Probably the best known example of this is spike-timing-dependent plasticity. Here, the timing of action potential firing in a presynaptic neuron and in a postsynaptic neuron determines whether synapses strengthen or weaken and by how much (Debanne et al., 1994; Markram et al., 1997; Bi and Poo, 1998). Computational studies indicate that spike-timing-dependent plasticity can support learning of temporal sequences, temporal difference learning, and the ability to predict future events from past stimuli (Feldman, 2012). In principle, therefore, cortical circuits could be trained to contribute to time-dependent cognition.

Synaptic plasticity alters the strength of existing synapses, but does it also change the timing of synaptic responses? We noted above that the synaptic latency changes little during short-term synaptic plasticity (Barnes et al., 2015). Furthermore, synaptic latency is preserved during experience-dependent plasticity, when changes in synaptic strength are accompanied by structural changes at synapses (Cheetham et al., 2008; Cheetham et al., 2014; Barnes et al., 2015). However, an exception to this general rule has been identified in cortex that is undergoing extensive, experience-dependent connection loss: synaptic latency is not maintained at recurrent excitatory connections that have been weakened (Barnes et al., 2015).

Reconfiguration of the architecture of cortical circuits, either by forming new connections to recruit neurons into a network or by losing connections to expel neurons from the network, is a form of rewiring (Barnes and Finnerty, 2010). During experience-dependent plasticity, new connections between pyramidal neurons $(\mathrm{Pyr} \rightarrow \mathrm{Pyr})$ can be formed within a few days. These $\mathrm{Pyr} \rightarrow \mathrm{Pyr}$ connections typically comprise multiple synapses. Despite the relatively rapid formation of new $\mathrm{Pyr} \rightarrow \mathrm{Pyr}$ connections, their synaptic latency and short-term synaptic dynamics are normal (Albieri et al., 2015). In contrast, $\mathrm{Pyr} \rightarrow \mathrm{Pyr}$ connections that are weakened and are in danger of being lost exhibit prolonged synaptic latency and diminished temporal precision of neurotransmission (Barnes et al., 2015).

The ability to vary the latency and precision of neurotransmission has consequences for firing of action potentials in recurrent excitatory networks. In the neocortex, recurrent excitatory connections are weak (Bruno and Sakmann, 2006; Cheetham et al., 2007), which means that multiple presynaptic neurons must fire synchronously to drive the membrane potential of the postsynaptic neuron to the firing threshold (Crochet et al., 2011). Delaying the synaptic response of a subset of the presynaptic neurons can alter the number and timing of spikes fired by the postsynaptic neuron (Barnes et al., 2015). Delaying the postsynaptic response offers a mechanism to remove a neuron functionally from a network. It has been proposed that this enables the effects of losing an established connection to be tested without physical destruction of the connection. This would allow the process of connection loss to be reversed if spiking output is adversely affected (Barnes et al., 2015).

There has been a drive to characterize the architecture of the neural circuits in the brain termed the connectome. However, it is not clear that knowing the brain's wiring diagram in isolation will enable predictions about neural activity in real time. The configuration of excitatory and inhibitory connections within the circuit will affect the time taken for activity to propagate through that circuit (Siegel et al., 2015). If we are to understand timedependent cognition, then we need to integrate the timing of neural activity into the connectome. This combination will provide a stronger basis for understanding cognition in behaving subjects.

\section{Mechanisms of temporal processing on the millisecond to second scale}

The mechanisms that allow the brain to tell time in the range of milliseconds and seconds remain, for the most part, a mystery (Mauk and Buonomano, 2004; Ivry and Schlerf, 2008; Merchant et al., 2013). For example, it is not clear how cortical circuits discriminate or reproduce specific durations (Jazayeri and Shadlen, 2010; Laje et al., 2011; Merchant et al., 2013) or anticipate the emergence of a stimulus that generally follows a cue by a fixed interval (Nobre et al., 2007; Cravo et al., 2013). In addressing these issues, it is first necessary to acknowledge that the brains of animals tell time across scales spanning $>12$ orders of magnitude, from detecting microsecond differences in interaural delays 
to tracking the $24 \mathrm{~h}$ cycle of the rotation of the Earth. It is clear that, across these time scales, the brain uses fundamentally different mechanisms and areas to tell time. For example, in the extremes, one can see that the microsecond timing necessary for sound localization is independent of the molecular clocks that track the $24 \mathrm{~h}$ cycles that govern our circadian rhythms (Buonomano, 2007).

Within the range of milliseconds to seconds, however, a longstanding debate has focused on the degree to which different temporal ranges and tasks may or may not rely on shared mechanisms. Models of the passage of time have been divided into two classes (Ivry and Schlerf, 2008; Muller and Nobre, 2014). One class comprises dedicated models that propose the presence of a centralized timer. The timer relies on specialized timing mechanisms that enable the timer to function as a master clock across a wide range of tasks. In contrast, the second class of models, termed intrinsic models, propose that most neural circuits are inherently capable of telling time and that temporal processing can be performed in many different brain areas on an as-needed basis.

A strong test of the intrinsic model would be to determine if cortical slices in vitro could, in effect, learn to tell time. This approach was taken by A. Goel and D. V. Buonomano (unpublished results) using optogenetic stimulation. Specifically, organotypic slices were trained by pairing electrical activity and light at intervals of 100, 250, or $500 \mathrm{~ms}$. In such slices, electrical stimulation can evoke polysynaptic activity; that is, a pattern of network activity produced by the internal dynamics of the network. Analysis of the temporal structure of the network activity evoked by the trained and untrained pathway was significantly different and the pattern evoked by the trained pathway reflected the trained interval; that is, there was an increased likelihood of observing events around the time of the expected interval. Mechanistic analyses suggested that the interval learning relied in part on time-varying changes in the balance of excitation and inhibition.

These results are consistent with the notion that, because timing is such an important computation, it is also one that cortical circuits are intrinsically capable of learning. The observed timing appears to rely on the neural dynamics generated by the recurrent circuitry. Understanding such dynamics, however, has proven to be a long-standing challenge at the computational level in part because the dynamic regimes generated by recurrent neural networks capable of supporting self-perpetuating activity tend to be chaotic - that is, highly sensitive to noise and thus not reproducible (Sompolinsky et al., 1988). The chaos problem has recently been addressed using computational models based on firing rate units (Laje and Buonomano, 2013). Moreover, it has been shown that it is possible to tune the weights of recurrent networks in a manner that the network will generate complex but stable neural trajectories. These trajectories effectively implement a "dynamic attractor." Specifically, rather than the dynamics of an attractor converging to a standard fixed point that represents a memory, the memory is a spatiotemporal "object" represented in the evolving neural trajectory. Although it is not known how such pattern could emerge in spiking networks in an unsupervised fashion (Liu and Buonomano, 2009; Litwin-Kumar and Doiron, 2012), these results establish that recurrent networks can generate computationally powerful regimes with long memories and provide a robust and flexible manner to encode time. Importantly a strength of these models is that they do not only encode simple temporal intervals or durations, but rather complex temporal patterns such as those necessary for speech recognition or production (Buonomano and Maass, 2009; Buonomano and Laje, 2010).

\section{Planning, decision making, and the encoding of time}

A hallmark of cognitive functions such as planning, anticipating, and deciding is the ability to process information over an extended time frame. For example, to hit a flying tennis ball, the brain must integrate sensory and motor information over hundreds of milliseconds. Similarly, to make a decision under uncertainty, the brain must assess the quality of information accrued over time.

Recent physiological recordings in animal models of higher brain function indicate that neurons involved in deliberation and planning are themselves time keepers (Brody et al., 2003; Janssen and Shadlen, 2005; Maimon and Assad, 2006; Hanks et al., 2011). A key feature of these neurons is their ability to maintain high discharge rates, persistent activity, in the absence of any direct sensory input and motor output. Although the synaptic and biophysical underpinnings of persistent activity are not known, it is thought that the modulations of this persistent activity, which we refer to as firing-rate dynamics, allow these neurons to track time.

Prior studies have examined how firing rate dynamics in different sensorimotor brain regions might represent time in behavioral tasks. For example, the firing rate of many neurons in the lateral intraparietal cortex either increases or decreases with elapsed time when monkeys categorize an interval as shorter or longer than a standard interval (Leon and Shadlen, 2003). This is a type of sensory timing. Conversely, when a sensory cue is used as a "go" signal, the firing rate of neurons associated with the motor response represent a hazard function of the expected cue (Janssen and Shadlen, 2005). Finally, when animals are asked to produce a time interval proactively (i.e., motor timing), neurons could exhibit complex patterns of firing rate dynamics at both the level of single neurons and across the population (Merchant et al., 2011; Schneider and Ghose, 2012; Crowe et al., 2014). In many brain areas, a primary component of the dynamics is a linear increase in firing rates (Maimon and Assad, 2006; Mita et al., 2009), which we refer to as ramping activity. These findings underline the importance of the firing-rate dynamics of sensorimotor neurons in timing. However, the computational principles that coordinate sensory and motor timing remain elusive.

A hint of the underlying mechanism comes from a recent study in which monkeys were trained to measure a sample time interval and then reproduce that interval as accurately as possible (Jazayeri and Shadlen, 2015). Analysis of the animals' behavior indicated that they learned to reproduce the time interval accurately using a Bayesian strategy, as shown previously in humans (Jazayeri and Shadlen, 2010). Extracellular recording from neurons in the lateral intraparietal area revealed distinct firing rate dynamics during the measurement and production phases of the task. Neural responses in the measurement phase had a nonlinear profile that increased monotonically with the duration of the sample interval. In contrast, firing rates in the production phase increased linearly and the slope of this ramping activity encoded the production interval on a trial-by-trial basis. Importantly, the firing rates in the measurement and production were linked. Specifically, the nonlinear firing rate dynamics in the measurement phase predicted the slope of ramp in the production phase. Therefore, in the measurement phase, the firing rate dynamics anticipated the slope of the ramping activity in the production phase, whereas, during the production phase, the firing rate dynamics anticipated the time of the upcoming motor response. These findings raise an intriguing idea. Just as knowledge (gnosis) 
of space appears to correlate with persistent activity associated with intention to look toward, reach for, or grasp (MerleauPonty, 1962; Shadlen et al., 2008), so might our sense of time correlate with dynamical activity associated with intention to reproduce, tap, or stomp.

\section{Temporal attention: using temporal regularities to anticipate sensory events}

Timing is a major determinant of the environment that we experience. Although our introspection suggests that we apprehend the entirety of our surroundings, many decades of empirical research teach us instead that our perception is highly limited. At most, a handful of items occupy our mind and guide our actions at any given moment (Helmholtz, 1867; James, 1890; Simons and Levin, 1997; Mack and Rock, 1998). When all works well, our perception is proactively and selectively focused on currently relevant events to guide adaptive behavior. These privileged percepts, extracted from countless other possibilities, provide the footing for our thoughts, decisions, and memories.

The functions responsible for goal-based prioritization of information processing are typically investigated under the domain of "attention." According to prevailing models of attention, representations related to current task goals modulate ("bias") neuronal excitability throughout sensory cortices to facilitate processing of relevant stimuli and suppress distraction from competing, irrelevant stimuli (Nobre and Kastner, 2014). Until recently, most efforts have gone into understanding top-down modulation of neuronal activity. This work has revealed mechanisms for spatial and feature-based attention. It is only recently, however, that researchers have recognized the essential role of temporal attention.

There are multiple sources of temporal regularities in the environment. The brain is able to make use of these to optimize the selection of the relevant items and events occurring at the right moments. Therefore, top-down biases not only carry information about receptive field properties, but also harbor information about how those receptive field properties are likely to unfold in time (Nobre et al., 2007; Nobre et al., 2012; Nobre and Rohenkohl, 2014).

Temporal expectations can be based on a variety of factors, including the natural rhythm of events, their consistent evolving temporal conditional probability for occurring within a given context (hazard rates), or their fixed temporal associations to other events (cues). Behavioral studies in human observers show that temporal expectation can improve perceptual sensitivity and response times when detecting or discriminating task-relevant stimuli (Jones, 1976; Coull and Nobre, 1998; Rohenkohl et al., 2012; Vangkilde et al., 2012). However, it is not clear how cortical circuits anticipate the emergence of a stimulus after the predicted time interval.

Brain imaging studies relying on hemodynamic measures have implicated a cortical network of parietal and inferior frontal areas in temporal orienting of attention (Coull and Nobre, 1998; Coull and Nobre, 2008). Noninvasive recording studies with high temporal resolution have been aimed at revealing modulatory mechanisms. Different sources of temporal expectationsrhythms, hazards, and cues - may use at least partially dissociable mechanisms. In all cases, however, changes in the timing or power of ongoing low-frequency oscillations have been observed (Cravo et al., 2011, 2013). These findings place critical constraints on models of how neural oscillations contribute to the prioritization, coordination, and routing of neural information to select and integrate features of relevant events. Interestingly, recording studies have also revealed that temporal expectations combine synergistically with expectations about stimulus location to enhance early perceptual analysis of incoming stimuli (Doherty et al., 2005; Rohenkohl et al., 2014). One possibility is that the topdown modulation of perceptual processing attributable to temporal expectations may rely heavily on foreknowledge of other stimulus attributes coded in receptive-field properties. Such a scheme might suggest that timing becomes an intrinsic part of anticipatory circuits as a consequence of rhythmic or learned relations among events.

\section{Conclusion}

The nature of time has been debated extensively. What has emerged is that our perception of time does not accurately reflect an objective reality external to ourselves (Kant, 1781; James, 1890; McTaggart, 1908). Furthermore, time-dependent cognition is fundamentally different from other sensory domains in that there is no sensory organ for time. Instead, our perception of time is generated internally within our brains. Our capacity for time-dependent cognition enables us to focus our attention and interact in real time with a rapidly changing environment. The temporal features of neural activity in cortical circuits and their capacity for plasticity suggest that cortical circuits can play a central role in many forms of time-dependent cognition. The cellular and network mechanisms that we review here are general properties of neural circuits. Therefore, they are not limited to the cortex and apply equally well to more distributed neural circuits that have been hypothesized to contribute to timing and temporal processing. Finally, we propose that an understanding of how the brain tells time and operates in time will be necessary to develop general models of brain function.

\section{References}

Albieri G, Barnes SJ, de Celis Alonso B, Cheetham CE, Edwards CE, Lowe AS, Karunaratne H, Dear JP, Lee KC, Finnerty GT (2015) Rapid bidirectional reorganization of cortical microcircuits. Cereb Cortex 25:30253035. CrossRef Medline

Allman MJ, Teki S, Griffiths TD, Meck WH (2014) Properties of the internal clock: first- and second-order principles of subjective time. Annu Rev Psychol 65:743-771. CrossRef Medline

Barnes SJ, Finnerty GT (2010) Sensory experience and cortical rewiring. Neuroscientist 16:186-198. CrossRef Medline

Barnes SJ, Cheetham CE, Liu Y, Bennett SH, Albieri G, Jorstad AA, Knott GW, Finnerty GT (2015) Delayed and temporally imprecise neurotransmission in reorganizing cortical microcircuits. J Neurosci 35:9024-9037. CrossRef Medline

Bi GQ, Poo MM (1998) Synaptic modifications in cultured hippocampal neurons: dependence on spike timing, synaptic strength, and postsynaptic cell type. J Neurosci 18:10464-10472. Medline

Brody CD, Romo R, Kepecs A (2003) Basic mechanisms for graded persistent activity: discrete attractors, continuous attractors, and dynamic representations. Curr Opin Neurobiol 13:204-211. CrossRef Medline

Bruno RM, Sakmann B (2006) Cortex is driven by weak but synchronously active thalamocortical synapses. Science 312:1622-1627. CrossRef Medline

Buonomano DV (2007) The biology of time across different scales. Nat Chem Biol 3:594-597. CrossRef Medline

Buonomano DV, Laje R (2010) Population clocks: motor timing with neural dynamics. Trends Cogn Sci 14:520-527. CrossRef Medline

Buonomano DV, Maass W (2009) State-dependent computations: spatiotemporal processing in cortical networks. Nat Rev Neurosci 10:113-125. CrossRef Medline

Cheetham CE, Hammond MS, Edwards CE, Finnerty GT (2007) Sensory experience alters cortical connectivity and synaptic function site specifically. J Neurosci 27:3456-3465. CrossRef Medline

Cheetham CE, Hammond MS, McFarlane R, Finnerty GT (2008) Altered sensory experience induces targeted rewiring of local excitatory connections in mature neocortex. J Neurosci 28:9249-9260. CrossRef Medline

Cheetham CE, Barnes SJ, Albieri G, Knott GW, Finnerty GT (2014) Pansyn- 
aptic enlargement at adult cortical connections strengthened by experience. Cereb Cortex 24:521-531. CrossRef Medline

Coull J, Nobre A (2008) Dissociating explicit timing from temporal expectation with fMRI. Curr Opin Neurobiol 18:137-144. CrossRef Medline

Coull JT, Nobre AC (1998) Where and when to pay attention: the neural systems for directing attention to spatial locations and to time intervals as revealed by both PET and fMRI. J Neurosci 18:7426-7435. Medline

Cravo AM, Rohenkohl G, Wyart V, Nobre AC (2011) Endogenous modulation of low frequency oscillations by temporal expectations. J Neurophysiol 106:2964-2972. CrossRef Medline

Cravo AM, Rohenkohl G, Wyart V, Nobre AC (2013) Temporal expectation enhances contrast sensitivity by phase entrainment of low-frequency oscillations in visual cortex. J Neurosci 33:4002-4010. CrossRef Medline

Crochet S, Poulet JF, Kremer Y, Petersen CC (2011) Synaptic mechanisms underlying sparse coding of active touch. Neuron 69:1160-1175. CrossRef Medline

Crowe DA, Zarco W, Bartolo R, Merchant H (2014) Dynamic representation of the temporal and sequential structure of rhythmic movements in the primate medial premotor cortex. J Neurosci 34:11972-11983. CrossRef Medline

Debanne D, Gähwiler BH, Thompson SM (1994) Asynchronous pre- and postsynaptic activity induces associative long-term depression in area CA1 of the rat hippocampus in vitro. Proc Natl Acad Sci U S A 91:11481152. CrossRef Medline

Doherty JR, Rao A, Mesulam MM, Nobre AC (2005) Synergistic effect of combined temporal and spatial expectations on visual attention. J Neurosci 25:8259-8266. CrossRef Medline

Feldman DE (2012) The spike-timing dependence of plasticity. Neuron 75: 556-571. CrossRef Medline

Fraisse P (1964) The psychology of time. London: Eyre and Spottiswode.

Fraisse P (1984) Perception and estimation of time. Annu Rev Psychol 35: 1-36. CrossRef Medline

Frankland PW, Bontempi B (2005) The organization of recent and remote memories. Nat Rev Neurosci 6:119-130. Medline

Hanks TD, Mazurek ME, Kiani R, Hopp E, Shadlen MN (2011) Elapsed decision time affects the weighting of prior probability in a perceptual decision task. J Neurosci 31:6339-6352. CrossRef Medline

Helmholtz H (1867) Handbook of physiological optics. Leipzig: Leopold Voss.

Ivry RB (1996) The representation of temporal information in perception and motor control. Curr Opin Neurobiol 6:851-857. CrossRef Medline

Ivry RB, Schlerf JE (2008) Dedicated and intrinsic models of time perception. Trends Cogn Sci 12:273-280. CrossRef Medline

James W (1890) The principles of psychology. London: MacMillan.

Janssen P, Shadlen MN (2005) A representation of the hazard rate of elapsed time in macaque area LIP. Nat Neurosci 8:234-241. CrossRef Medline

Jazayeri M, Shadlen MN (2010) Temporal context calibrates interval timing. Nat Neurosci 13:1020-1026. CrossRef Medline

Jazayeri M, Shadlen MN (2015) A neural mechanism for sensing and reproducing a time interval. Curr Biol. In press.

Jones MR (1976) Time, our lost dimension: toward a new theory of perception, attention, and memory. Psychol Rev 83:323-355. CrossRef Medline

Kant I (1781) Critique of pure reason. Retranslated and republished in 1998 by Cambridge UP.

Katz B, Miledi R (1965) The measurement of synaptic delay, and the time course of acetylcholine release at the neuromuscular junction. Proc R Soc Lond B Biol Sci 161:483-495. CrossRef Medline

Laje R, Buonomano DV (2013) Robust timing and motor patterns by taming chaos in recurrent neural networks. Nat Neurosci 16:925-933. CrossRef Medline

Laje R, Cheng K, Buonomano DV (2011) Learning of temporal motor patterns: an analysis of continuous versus reset timing. Front Integr Neurosci 5:61. Medline

Leon MI, Shadlen MN (2003) Representation of time by neurons in the posterior parietal cortex of the macaque. Neuron 38:317-327. CrossRef Medline

Litwin-Kumar A, Doiron B (2012) Slow dynamics and high variability in balanced cortical networks with clustered connections. Nat Neurosci 15: 1498-1505. CrossRef Medline

Liu JK, Buonomano DV (2009) Embedding multiple trajectories in simulated recurrent neural networks in a self-organizing manner. J Neurosci 29:13172-13181. CrossRef Medline

Mack A, Rock I (1998) Intentional blindness. Cambridge, MA: MIT.

Maimon G, Assad JA (2006) A cognitive signal for the proactive timing of action in macaque LIP. Nat Neurosci 9:948-955. CrossRef Medline

Markram H, Lübke J, Frotscher M, Sakmann B (1997) Regulation of synaptic efficacy by coincidence of postsynaptic APs and EPSPs. Science 275: 213-215. CrossRef Medline

Martin SJ, Grimwood PD, Morris RG (2000) Synaptic plasticity and memory: an evaluation of the hypothesis. Annu Rev Neurosci 23:649-711. CrossRef Medline

Mauk MD, Buonomano DV (2004) The neural basis of temporal processing. Annu Rev Neurosci 27:307-340. CrossRef Medline

McTaggart JE (1908) The unreality of time. Mind 17:457-474.

Merchant H, Zarco W, Pérez O, Prado L, Bartolo R (2011) Measuring time with different neural chronometers during a synchronizationcontinuation task. Proc Natl Acad Sci U S A 108:19784-19789. CrossRef Medline

Merchant H, Harrington DL, Meck WH (2013) Neural basis of the perception and estimation of time. Annu Rev Neurosci 36:313-336. CrossRef Medline

Merleau-Ponty M (1962) Phenomenology of perception. London: Routledge and Kegan Paul.

Mita A, Mushiake H, Shima K, Matsuzaka Y, Tanji J (2009) Interval time coding by neurons in the presupplementary and supplementary motor areas. Nat Neurosci 12:502-507. CrossRef Medline

Muller T, Nobre AC (2014) Perceiving the passage of time: neural possibilities. Ann N Y Acad Sci 1326:60-71. CrossRef Medline

Nobre AC, Kastner S (2014) Handbook of attention. Oxford: OUP.

Nobre AC, Rohenkohl G (2014) Time for the fourth dimension in attention. Oxford: OUP.

Nobre AC, Rohenkohl G, Stokes MG (2012) Nervous anticipation: topdown biaising across space and time. New York: Gulliford.

Nobre A, Correa A, Coull J (2007) The hazards of time. Curr Opin Neurobiol 17:465-470. CrossRef Medline

Pouille F, Scanziani M (2001) Enforcement of temporal fidelity in pyramidal cells by somatic feed-forward inhibition. Science 293:1159-1163. CrossRef Medline

Rohenkohl G, Cravo AM, Wyart V, Nobre AC (2012) Temporal expectation improves the quality of sensory information. J Neurosci 32:8424-8428. CrossRef Medline

Rohenkohl G, Gould IC, Pessoa J, Nobre AC (2014) Combining spatial and temporal expectations to improve visual perception. J Vis 14.

Sabatini BL, Regehr WG (1996) Timing of neurotransmission at fast synapses in the mammalian brain. Nature 384:170-172. CrossRef Medline

Schneider BA, Ghose GM (2012) Temporal production signals in parietal cortex. PLoS Biol 10:e1001413. CrossRef Medline

Shadlen MN, Kiani R, Hanks TD, Churchland AK (2008) Neurobiology of decision making: an intentional framework. In: Better than conscious?: Decision making, the human mind and implications for institutions (Engel C, Singer W, eds). Cambridge, MA: MIT

Siegel M, Buschman TJ, Miller EK (2015) Cortical information flow during flexible sensorimotor decisions. Science 348:1352-1355. CrossRef Medline

Silva AJ, Zhou Y, Rogerson T, Shobe J, Balaji J (2009) Molecular and cellular approaches to memory allocation in neural circuits. Science 326:391-395. CrossRef Medline

Simons DJ, Levin DT (1997) Change blindness. Trends Cogn Sci 1:261-267. CrossRef Medline

Sompolinsky H, Crisanti A, Sommers HJ (1988) Chaos in random neural networks. Phys Rev Lett 61:259-262. CrossRef Medline

Vangkilde S, Coull JT, Bundesen C (2012) Great expectations: temporal expectation modulates perceptual processing speed. J Exp Psychol Hum Percept Perform 38:1183-1191. CrossRef Medline

Zucker RS, Regehr WG (2002) Short-term synaptic plasticity. Annu Rev Physiol 64:355-405. CrossRef Medline 